\title{
Analysis of the stability of slopes reinforced by roots
}

\author{
F. Gentile ${ }^{1}$, G. Elia $^{2}$ \& R. Elia ${ }^{1}$ \\ ${ }^{I}$ Department of Engineering and Management of the Agricultural, \\ Livestock and Forest Systems (PROGESA), University of Bari, Italy \\ ${ }^{2}$ School of Civil Engineering and Geosciences $(\mathrm{Ce} G)$, \\ Newcastle University, UK
}

\begin{abstract}
This paper deals with the assessment of vegetation contribution to slope stability, with particular emphasis on the mechanical effects provided by the root system. As is well known the presence of roots within the soil increases, with respect to the case of soil without vegetation, the material effective cohesion with no significant change in its friction angle. Such mechanical effect can be introduced in the Mohr-Coulomb failure law through an "apparent cohesion" term, which adds to the soil effective cohesion.

The contribution of root reinforcement to the soil shear strength has been investigated in slope stability finite element analyses, modifying the soil properties of individual slope elements including vegetation. This approach allowed quantification of the effect of the mechanical root reinforcement on the slope factor of safety and assessment of the sensitivity of slope stability to the variation of apparent cohesion and root zone depth assumed in the numerical simulations.
\end{abstract}

Keywords: slope stability, root reinforcement, apparent cohesion, finite element method.

\section{Introduction}

The presence of a root system in the soil plays an important role on the stability of natural slopes, which are usually covered with vegetation. It affects the stability of a slope, essentially through hydrological and mechanical effects. Regarding the latter aspect, the density of roots within the soil mass and their 
tensile strength contribute to improve the capacity of the soil to resist shear loads (Figure 1). The maximum tensile strength or pull-out resistance of the roots, together with an assessment of the root size and distribution (Root Area Ratio), can be used to evaluate the appropriate root reinforcement values to be used in the stability analysis of a slope. Many authors have provided values of root system depths and the tensile strength of different species of herbaceous and shrub types. In particular, the experimental data obtained from direct shear tests performed on blocks of soil containing roots have shown that the presence of vegetation produces an increase in soil cohesion, leaving its friction angle unchanged (Wu et al. [1], Faisal and Normaniza [2]).

Such mechanical effect can be introduced in the Mohr-Coulomb failure law through an "apparent cohesion" term, which adds to the soil effective cohesion (Gentile et al. [3]):

$$
\tau=\left(c^{\prime}+c_{R}\right)+\sigma^{\prime} \tan \varphi^{\prime}=\left(c^{\prime}+c_{R}\right)+(\sigma-u) \tan \phi^{\prime}
$$

where $\tau$ is the shear stress on the failure plane, $\sigma^{\prime}$ represents the effective stress normal to this plane (equal to the difference between the total normal stress $\sigma$ and the pore water pressure $u), c^{\prime}$ is the effective cohesion, $c_{R}$ the apparent cohesion and $\phi^{\prime}$ is the effective friction angle of the soil.

The apparent cohesion $c_{R}$ can be expressed as (Norris and Greenwood [4]):

$$
\mathrm{c}_{\mathrm{R}}=1.2 \mathrm{~T}_{\mathrm{R}}\left(\mathrm{A}_{\mathrm{R}} / \mathrm{A}\right)
$$

where $T_{R}$ is the mean tensile strength of the roots and $A_{R} / A$ is the cross-section of soil occupied by the roots (Root Area Ratio).

Wu et al. [5] have studied the stability of slopes before and after the removal of forest cover, incorporating the apparent cohesion due to roots in the limit equilibrium analysis of infinite slopes. The authors have shown how it is possible in this way to increase the safety factor of the analysed slopes, therefore concluding that the contribution to shear strength provided by the root system is crucial in studying the stability of natural slopes.

Recently, Chok et al. [6] have analysed the mechanical effect due to vegetation on the stability of ideal slopes, using a numerical code based on the finite element method (Zienkiewicz and Taylor [7]). The method, widely employed for the numerical solution of different engineering problems, allow the user to easily define the extent of the vegetation effects, being the slope geometry discretised into small elements. Moreover, the approach provides

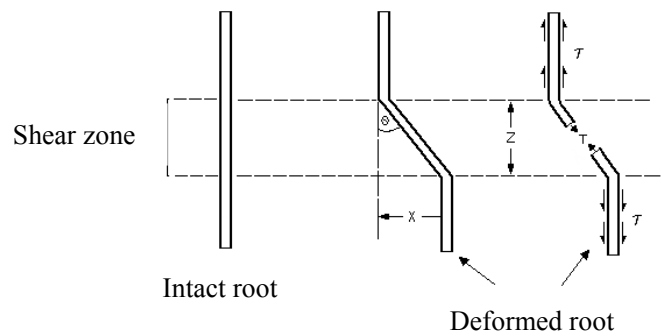

Figure 1: Schematization of root reinforcement (from Gentile et al. [3]). 
information about the overall stability of the slope as the value of the factor of safety (FOS) on the critical slip surface can be derived through the $\mathrm{c}^{\prime}-\phi^{\prime}$ reduction technique (Griffiths and Lane [8]).

The work describes the analysis of the mechanical effect of root systems on slope stability using the finite element code PLAXIS 2D [9] and adopting an approach similar to that proposed by Chok et al. [6].

\section{Tensile and shear strength of roots}

\subsection{Tensile strength}

According to the literature, the values of roots tensile strength generally depend on various factors: species, dimensions, morphology and spatial directions (Figure 2).

Stress-strain curves obtained by traction tests have been processed to obtain the peak tensile strength values. The laboratory data show that the tensile strength generally decreases with root diameter, as reported in Figure 3: root strengths are lower for large diameters and higher for small diameters (Bischetti et al. [11], Gray and Barker [12]). Moreover, root strength depends on the biological components of the root: smaller diameter roots have more cellulose than larger diameter roots and therefore are characterised by higher strength (Genet et al. [13]).

Regarding the distribution of roots in soil deposits, the observed values of Root Area Ratio (RAR) show a very high variability with species, location and depth. RAR is strongly influenced by genetics, local soil, climate characteristics and forest management; in addition, randomness must be accounted for. However, RAR usually decreases with depth as a consequence of a decrease of nutrients and aeration, and because of the presence of more compacted layers (Bischetti et al. [11]).

\subsection{Apparent cohesion}

The reliable benefit of apparent cohesion is limited to shallow depths as root distribution is mainly concentrated within $1 \mathrm{~m}$ from the ground surface
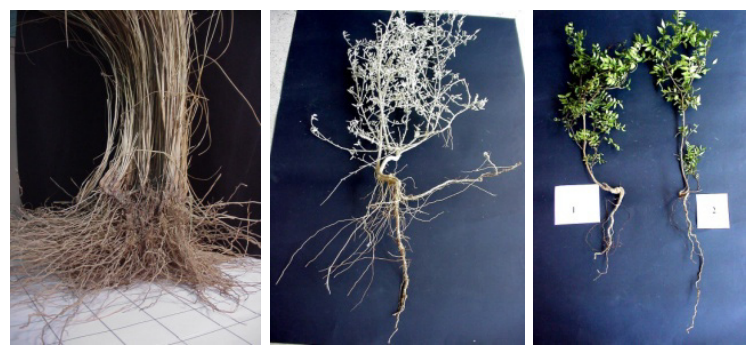

Figure 2: Morphological differences between root systems of different shrubby species (from Mattia et al. [10]). 


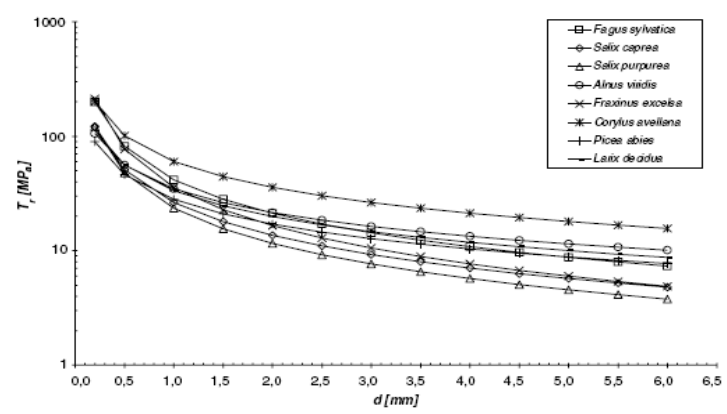

Figure 3: Strength-diameter fitting curves for different species (from Bischetti et al. [11]).

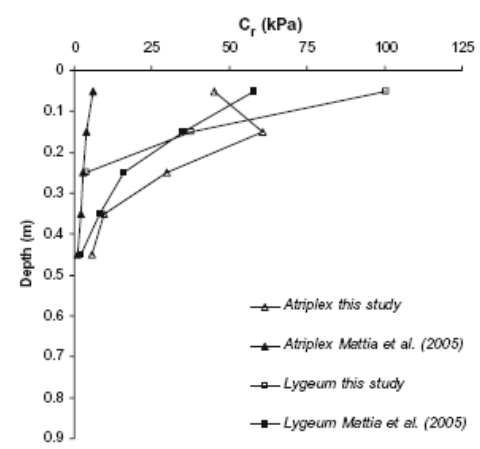

Figure 4: Value of root cohesion at different depths (from De Baets et al. [15]).

(Figure 4). The use of an enhanced value of the soil cohesion is appropriate for grass and shrub areas where fine root distribution with depth is consistent and easily defined (Norris and Greenwood [4]).

Field studies of forested slopes ( $\mathrm{O}^{\prime}$ Loughlin [14]) indicate that the fine roots, 1 to $20 \mathrm{~mm}$ in diameter, are the ones that contribute most to soil reinforcement. Grasses, legumes and small shrubs can have a significant reinforcing effect down to depths from 0.75 to $1.5 \mathrm{~m}$ (Faisal and Normaniza [2]).

Some researchers have attempted to compute the values of apparent cohesion due to the presence of the roots in the ground by designing and developing in situ shear tests for different types of root systems (O'Loughlin and Ziemer [16], Norris and Greenwood [17], van Beek et al. [18]).

\section{Vegetation effect on the stability of an ideal slope}

The contribution of root reinforcement to soil shear strength has been investigated by numerical stability analyses of ideal slopes in plane strain conditions using the two-dimensional finite element code PLAXIS 2D [9]. This 
approach has allowed to quantify the effect of the mechanical root reinforcement on the slope factor of safety (FOS), assessing the sensitivity of slope stability to the variation of apparent cohesion $\left(\mathrm{c}_{\mathrm{R}}\right)$ and root zone depth $\left(\mathrm{h}_{\mathrm{R}}\right)$ assumed in the numerical simulations. In particular, a slope characterised by the absence of water has been initially considered. The presence of vegetation has been simulated by attributing to the elements of the mesh representing the layer with presence of roots a value of effective cohesion higher than the one of the surrounding soil. Subsequently, an ideal slope with a water table at ground surface has been analysed.

\subsection{Case A: slope characterised by the absence of water and $\mathrm{c}^{\prime}=0 \mathrm{kPa}$}

The first case studied (Case A) is relative to an ideal slope with an inclination angle $\beta$ equal to $26.5^{\circ}$, composed by a homogeneous material $\left(\mathrm{c}^{\prime}=0 \mathrm{kPa}, \phi^{\prime}=25^{\circ}\right.$ and $\gamma=20 \mathrm{kN} / \mathrm{m}^{3}$ ) and characterised by the absence of water. The geometrical configuration of the slope and the adopted finite element mesh are shown in Figure 5.

At first, the stability of a homogeneous slope without vegetation $\left(\mathrm{c}_{\mathrm{R}}=0 \mathrm{kPa}\right)$ has been assessed. The result of this analysis has been taken as reference for the evaluation of the mechanical effects due to the presence of vegetation on the slope. Figure 6 shows the contour lines of shear strains at failure obtained at the end of the $c^{\prime}-\phi^{\prime}$ reduction analysis. The obtained shear strain values relate to a condition close to collapse and, therefore, have no physical sense. Nevertheless, they indicate the development of a planar and shallow failure mechanism inside the slope, with a maximum concentration of shear strains at its toe. The depth of the critical surface, measured at the centre of the slope, is equal to $1.4 \mathrm{~m}$ from ground level. The slope is characterised by a FOS close to one, consistently with what has been obtained by a limit equilibrium analysis.

The effect of the presence of vegetation on slope stability has been initially analysed attributing a value of apparent cohesion equal to $5 \mathrm{kPa}$ to a layer of soil elements disposed along the slope surface for a depth $h_{R}=1 \mathrm{~m}$. The introduction of vegetation confined along the slope surface only results in a small increment of the safety factor. If the slope toe elements are also treated as vegetated soil, the increment of the slope safety factor is more significant. Finally, the introduction of vegetation extending over the entire ground surface for a depth of

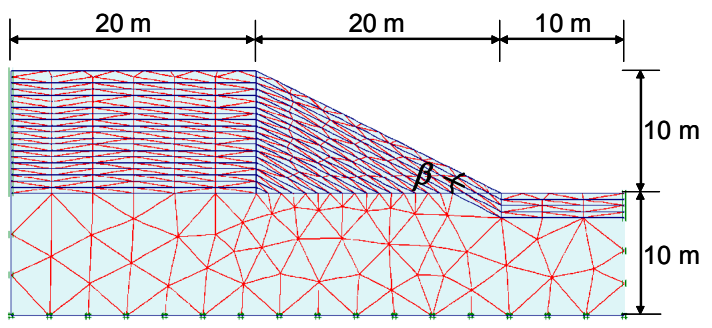

Figure 5: Adopted mesh for Cases A and B. 


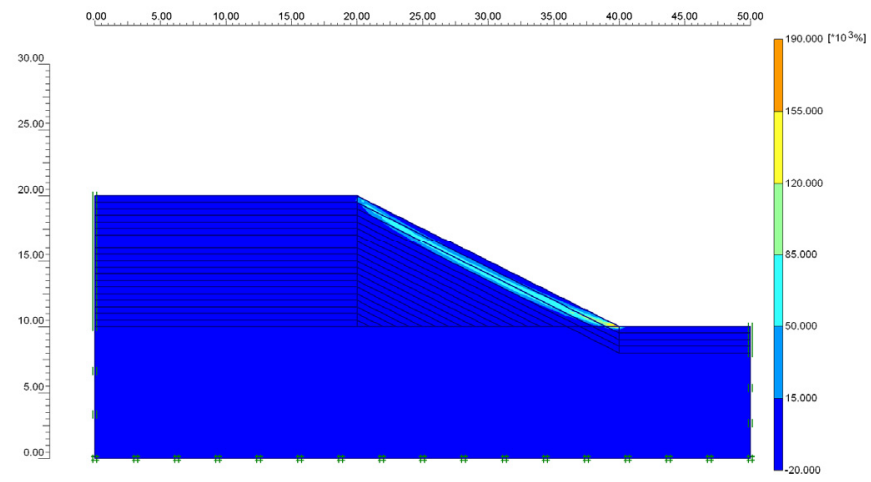

Figure 6: Contour lines of shear strains at failure for a slope without vegetation (Case A).

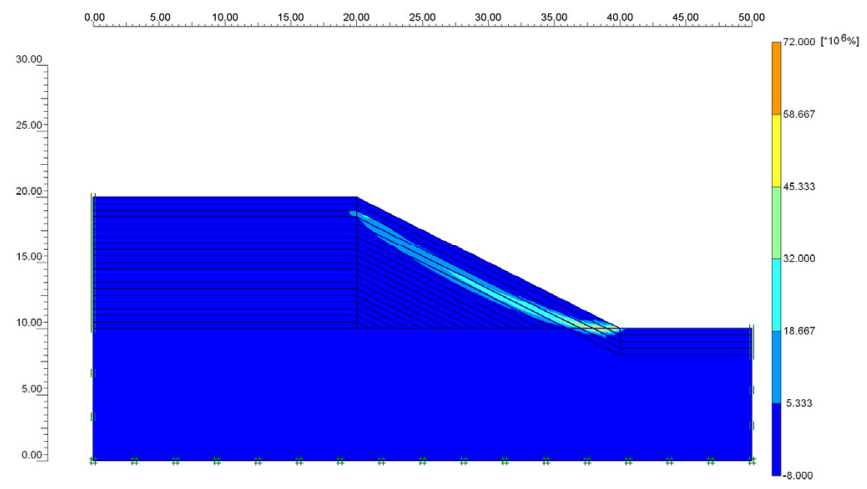

Figure 7: Contour lines of shear strains at failure for a slope with vegetation extending over the entire ground surface (Case A).

$1 \mathrm{~m}$ gives to the slope a FOS equal to 1.08 (an increase of $11.5 \%$ compared to the case without vegetation), producing a downward shift of the critical surface to a depth of $2.6 \mathrm{~m}$. The analysis shows how the presence of roots distributed uniformly throughout the slope have a positive effect on its stability, with a significant increment of the FOS. The effect increases as much as the root apparatus extends in depth, reaching the zones where the failure mechanism is initiated. Consequently, the critical slip surface is shifted deeper below the ground surface, becoming circular, as shown in Figure 7.

Parametric studies have been performed for a range of apparent root cohesion. Figure 8 shows the evolution of the slope FOS with the apparent root cohesion for $h_{R}=1 \mathrm{~m}$, when $c^{\prime}=0 \mathrm{kPa}$ and the vegetation is confined i) to the slope surface only, ii) slope and toe and iii) vegetation extends over the entire ground surface. The values of the critical surface depth with $c_{R}$ are shown with dashed line in the same figure. 


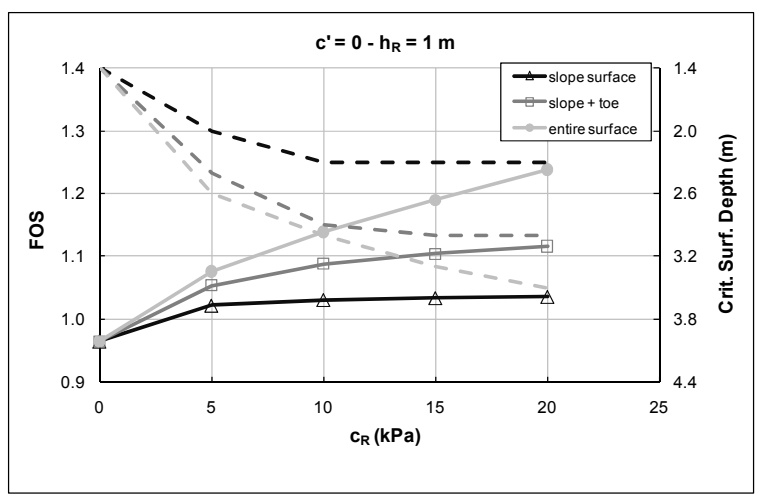

Figure 8: $\quad$ Evolution of FOS and critical surface depth with $\mathrm{c}_{\mathrm{R}}$ (Case A).

\subsection{Case B: slope characterised by the absence of water and $\mathrm{c}^{\prime}=5 \mathrm{kPa}$}

Case $B$ regards the same ideal slope of Case $A\left(\beta=26.5^{\circ}, \phi^{\prime}=25^{\circ}\right.$ and $\gamma=20 \mathrm{kN} / \mathrm{m}^{3}$ ), but composed of a soil with $\mathrm{c}^{\prime}=5 \mathrm{kPa}$. In this situation, the limit equilibrium analysis provides a critical slip surface that is no longer parallel to the surface, but circular and deep, with an associated FOS equal to 1.34.

This is confirmed by the contour lines of shear strains obtained through the finite element analysis, as shown in Figure 9. The critical surface starts from the toe of the slope, deepening up to $3.6 \mathrm{~m}$ from the ground level. In this case, the mechanical effect of vegetation on slope stability has been investigated by assigning a value of apparent cohesion of $10 \mathrm{kPa}$ to the soil elements affected by root reinforcement.

If the vegetation is only present on the slope surface for a depth $h_{R}=1 \mathrm{~m}$, the increase in the FOS is just equal to $0.1 \%$ with respect to the case of slope without vegetation. The depth of the critical surface does not change significantly. This confirms the limited effect of vegetation on slope stability when the sliding mechanism is deep and the root reinforcement is limited to the first layers below the surface. Assuming the presence of vegetation also at the toe of the slope, the FOS increases to 1.37 and the failure surface reaches a depth of $3.8 \mathrm{~m}$. Finally, if the vegetation covers the entire ground surface the slope safety factor reaches a value of 1.39. The depth of the corresponding failure surface (Figure 10), however, remains almost similar with respect to the case of vegetation covering slope surface and toe.

The sensitivity analysis indicates that the vegetation mechanical effects are less significant in slopes with high values of effective cohesion where deepseated failure mechanisms are likely to occur, as the FOS increments with $c_{R}$ are proportionally lower than the ones obtained in the case of the same slope with $\mathrm{c}^{\prime}=0 \mathrm{kPa}$ (Figure 11). 
196 Design and Nature V

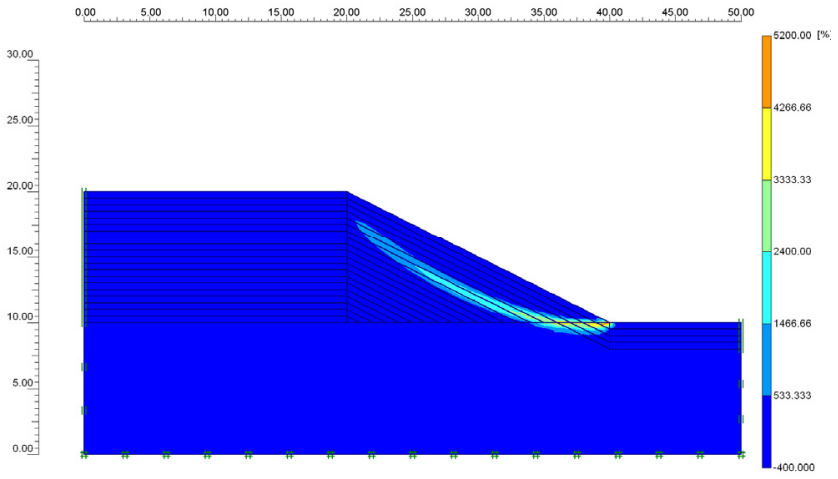

Figure 9: Contour lines of shear strains at failure for a slope without vegetation (Case B).

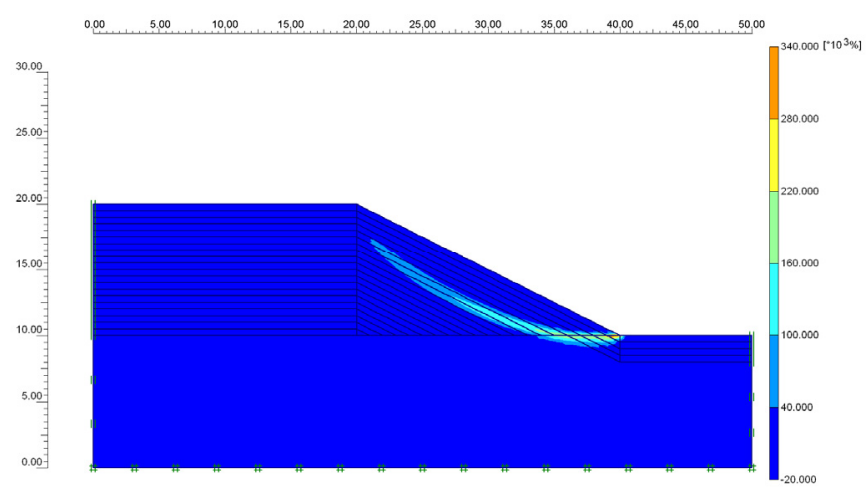

Figure 10: Contour lines of shear strains at failure for a slope with vegetation extending over the entire ground surface (Case B).

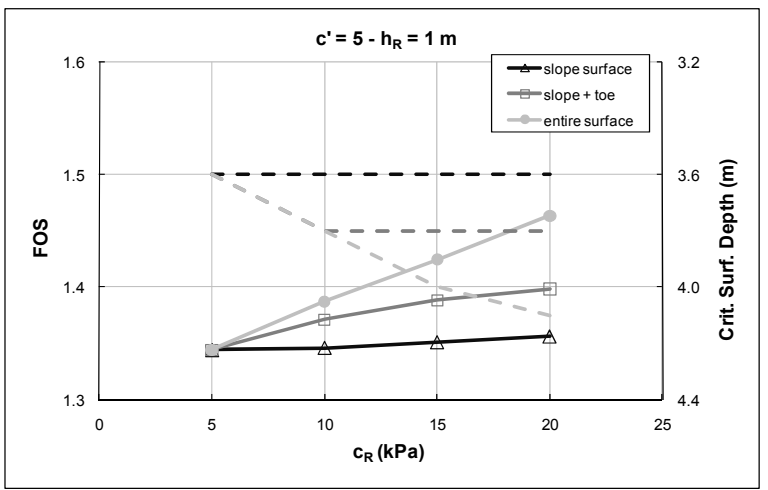

Figure 11: Evolution of FOS and critical surface depth with $\mathrm{c}_{\mathrm{R}}$ (Case B). 


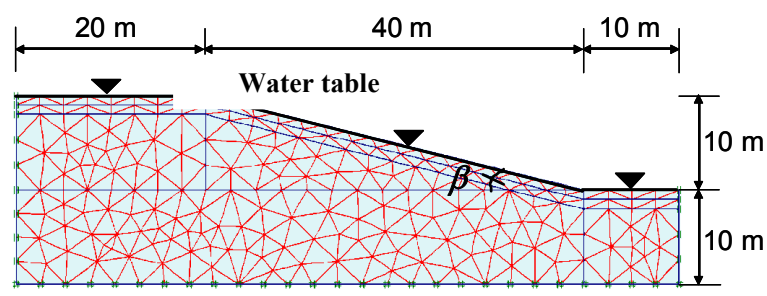

Figure 12: $\quad$ Adopted mesh for Case C.

\subsection{Case C: slope characterised by the existence of water and $\mathrm{c}^{\prime}=0 \mathrm{kPa}$}

The introduction of a water table at the ground surface in the slope of Case A would produce a significant reduction of the soil effective stress, leading to a FOS below one. The slope angle assumed in Cases A and B $\left(26.5^{\circ}\right)$ is, in fact, too high to account for the presence of a water table inside a homogeneous slope characterised by a soil friction angle of $25^{\circ}$ and a cohesion equal to zero.

The geometry of the ideal slope has been therefore changed, assuming, for the same slope height of $10 \mathrm{~m}$, a slope angle of $14^{\circ}$ and a soil friction angle of $30^{\circ}$. The adopted finite element mesh is shown in Figure 12. The reference case is now represented by an ideal slope composed by a homogeneous material with strength parameters $\mathrm{c}^{\prime}=0 \mathrm{kPa}$ and $\phi^{\prime}=30^{\circ}$, characterised by the presence of a water table at the ground surface in steady state conditions and without vegetation $\left(c_{R}=0 \mathrm{kPa}\right)$. In such a case, the FOS of the slope is equal to 1.10 and the corresponding critical surface, which develops from the toe of the slope, is almost parallel to the ground surface, with a depth of about $1.3 \mathrm{~m}$.

As in the previous cases, different distributions of root reinforcement along the slope has been considered, assigning an enhanced value of cohesion $\left(c_{R}=5 \mathrm{kPa}\right)$ to soil elements with presence of vegetation.

When the vegetation covers only the slope surface for a depth of $1 \mathrm{~m}$, the FOS slightly increases to 1.13 . It corresponds to a failure surface that remains approximately parallel to the ground surface. The effect of the increase of the safety factor and deepening of the critical surface is even more evident if the vegetation includes also the toe of the slope. In this case the FOS becomes 1.16, while the depth of the critical mechanism appears to be equal to $2.3 \mathrm{~m}$. The sliding surface deepens $(2.5 \mathrm{~m})$ when the roots extend over the entire ground surface (Figure 13) and tends to assume a circular shape. The corresponding FOS increases of $7.5 \%$ with respect to the case of slope without vegetation.

Also in Case $\mathrm{C}$ parametric studies have been performed changing the apparent root cohesion. The evolution of FOS and depth of the critical surface with apparent root cohesion (for $h_{R}=1 \mathrm{~m}$ ) is shown in Figure 14 and the results are similar to those of Case A. 


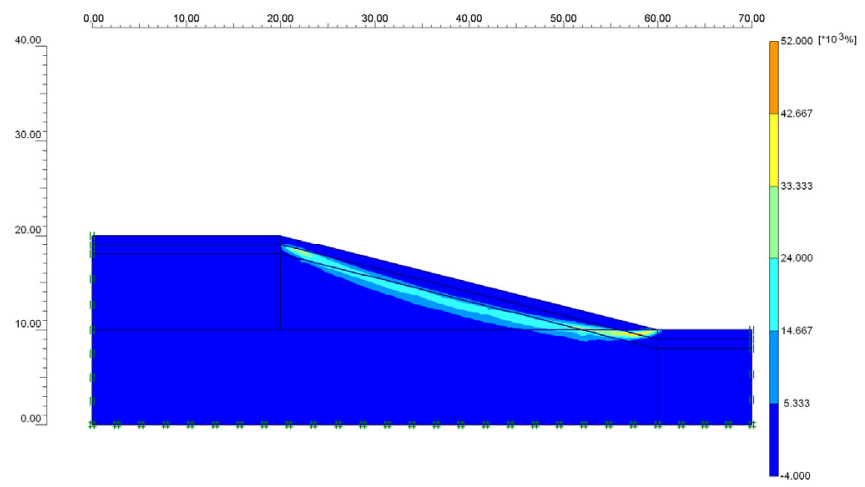

Figure 13: Contour lines of shear strains at failure for a slope with vegetation extending over the entire ground surface (Case C).

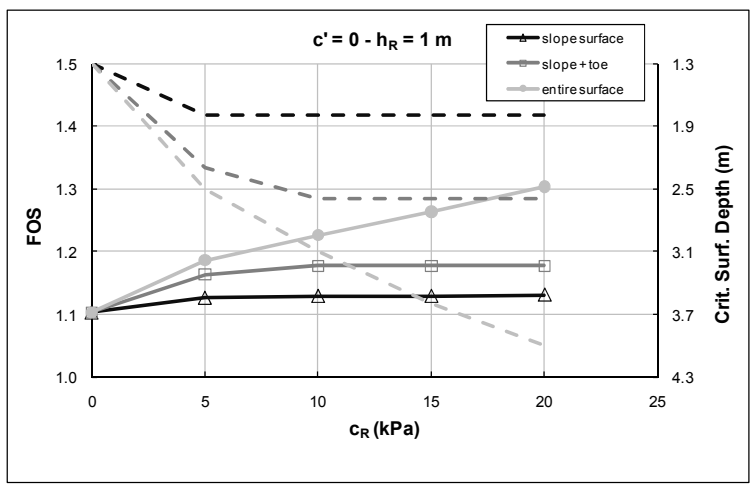

Figure 14: Evolution of FOS and critical surface depth with $\mathrm{c}_{\mathrm{R}}($ Case $\mathrm{C})$.

\section{Conclusions}

The work investigates the influence of vegetation on slope stability, with particular emphasis on the mechanical effects due to the presence of roots into the soil. The increase of the slope safety factor provided by root reinforcement has been evaluated using a two-dimensional finite element code enhancing the effective cohesion of individual slope elements with presence of vegetation.

When the failure mechanism inside a slope without vegetation starts from its toe and is planar and shallow, the introduction of vegetation confined along the slope surface only results in small increments of the safety factor. If the slope toe elements are treated as vegetated soil or the vegetation extends over the entire ground surface, the increment of the slope safety factor is more significant. In these cases, the effect increases as much as the root system extends in depth, reaching the zones where the failure mechanism is initiated. Consequently, the critical slip surface is shifted deeper below the ground surface, becoming 
circular. The sensitivity analysis indicates that the vegetation mechanical effects are less significant in slopes with high values of effective cohesion where deepseated failure mechanisms are likely to occur. Moreover, the existence of a water table at ground surface does not generate any considerable change in the general framework observed during finite element analyses of slopes without water.

\section{References}

[1] Wu, T.H., Beal, P.E. \& Lan, C., In situ shear test of soil-root system. Journal of Geotechnical Engineering, 114, pp. 1351-1375, 1988.

[2] Faisal, H.A. \& Normaniza, O., Shear strength of soil containing vegetation roots. Soils and Foundations, 48(4), pp. 587-596, 2008.

[3] Gentile, F., Romano, G. \& Trisorio-Liuzzi, G., L'uso della vegetazione negli interventi di difesa del suolo in ambiente mediterraneo. Genio Rurale, 2, pp. 42-51, 1998.

[4] Norris, J.E. \& Greenwood, J.R., Assessing the role of vegetation on soil slopes in urban areas. Proc. $10^{\text {th }}$ Congress of the International Association for Engineering Geology and the Environment (IAEG), Nottingham, UK, 2006.

[5] Wu, T.H., McKinnell, W.P. \& Swanston, D.N., Strength of tree root and landslides on Prince of Wales Island, Alaska. Canadian Geotechnical Journal, 16, pp. 19-33, 1979.

[6] Chok, Y.H., Kaggwa, W.S., Jaksa, M.B. \& Griffiths, D.V., Modelling the effect of vegetation on stability of slopes. Proc. $9^{\text {th }}$ Australia New Zealand Conference on Geomechanics, Auckland, 2004.

[7] Zienkiewicz, O.C. \& Taylor, R.L., The Finite Element Method, Wiley, John \& Sons, 1991.

[8] Griffiths, D.V. \& Lane, P.A., Slope stability analysis by finite elements. Géotechnique, 49(3), pp. 387-403, 1999.

[9] PLAXIS 2D, Reference Manual, Version 8, 2003.

[10] Mattia, C., Bischetti, G.B. \& Gentile, F., Biotechnical characteristics of root systems of typical Mediterranean species. Plant and Soil, 278, pp. 23-32, 2005.

[11] Bischetti, G.B., Chiaradia, E.A., Simonato, T., Speziali, B., Vitali, B., Vullo, P. \& Zocco, A., Root strength and root area ratio of forest species in Lombardy (Northern Italy). Plant and Soil, 278, pp. 11-22, 2005.

[12] Gray, D.H. \& Barker, D., Root-Soil Mechanics and Interactions, Riparian vegetation and fluvial geomorphology, Water Science and Application 8, American Geophysical Union, Washington DC, pp. 125-139, 2004.

[13] Genet, M., Stokes, A., Salin, F., Mickovski, S.B., Fourcaud, T., Dumail, J.F. \& van Beek, R., The influence of cellulose content on tensile strength in tree roots. Plant and Soil, 278, pp. 1-9, 2005.

[14] O'Loughlin, C.L., Effectiveness of introduced forest vegetation for protecting against landslides and erosion in New Zealand's steeplands. Proc. Symposium on effects of forest land use on erosion and slope stability, Honolulu, Hawaii, 1984. 
[15] De Baets, S., Poesen, J., Reubens, B., Wemans, K., De Baerdemaeker, J. \& Muys, B., Root tensile strength and root distribution of typical Mediterranean plant species and their contribution to soil shear strength. Plant and Soil, 305, pp. 207-226, 2008.

[16] O'Loughlin, C.L. \& Ziemer, R.R., The importance of root strength and deterioration rates upon edaphic stability in steepland forests. Proc. I.U.F.R.O. Workshop P.1.07-00 Ecology of subalpine ecosystems as a key to management, Oregon, USA, pp. 70-78, 1982.

[17] Norris, J.E. \& Greenwood, J.R., In-situ shear box and root pull-out apparatus for measuring the reinforcing effects of vegetation. Proc. Field Measurements in Geomechanics, Swets and Zeitlinger, Lisse, pp. 593-597, 2003.

[18] van Beek, L.P.H., Wint, J., Cammeraat, L.H. \& Edwards, J.P, Observation and simulation of root reinforcement on abandoned Mediterranean slopes. Plant and Soil, 278, pp. 55-74, 2005. 